Open Access

\title{
Current Status of Endoscope Reprocessing in Korea
}

\author{
Young-Seok Cho
}

Department of Internal Medicine, Uijeongbu St. Mary's Hospital, College of Medicine, The Catholic University of Korea, Uijeongbu, Korea

See "Survey of Endoscope Reprocessing in Korea" by Jeong Bae Park, Jae Nam Yang, Yun Jeong Lim, et al., on page 39-47

Gastrointestinal (GI) endoscopy has been widely used as a clinical diagnostic procedure in Korea since the introduction of the National Cancer Screening Program in 1999. Moreover, the use of endoscopic procedures to treat GI disorders is increasing rapidly. A review article published in 1993 reported 281 instances of pathogen transmission attributed to GI endoscopy between 1966 and 1992. ${ }^{1}$ A recent review found only 35 cases of infection transmission attributable to GI endoscopy since $1993 .^{2}$ However, the actual infection rate may have been underestimated because of underreporting, incomplete surveillance, asymptomatic infections, and infections with long incubation periods. In Korea, public concern over the risk of pathogen transmission during endoscopy has escalated following recent media reports of inadequate endoscope reprocessing. Recognition of the infection risks associated with inadequate cleaning and disinfection led several scientific societies to develop guidelines to minimize this risk and ensure maximum safety. ${ }^{3,4}$ In 1995, the Korean Society of Gastrointestinal Endoscopy developed cleaning and disinfection guidelines for GI endoscopes, which were revised and republished in November 2009 and August 2012. ${ }^{5}$ The guidelines emphasized the importance of strict adherence to cleaning, disinfection, and surveillance procedures to improve reprocessing quality. Moreover, survey reports on GI endoscope and accessory reprocessing practices have been conducted in several countries to improve reprocessing practices.

In this issue of Clinical Endoscopy, Park et al. ${ }^{6}$ present a

Received: December 9, 2014 Accepted: December 22, 2014

Correspondence: Young-Seok Cho

Department of Internal Medicine, Uijeongbu St. Mary's Hospital, College of Medicine, The Catholic University of Korea, 271 Cheonbo-ro, Uijeongbu 480717 , Korea

Tel: +82-31-820-3658, Fax: +82-31-847-2719, E-mail: yscho@catholic.ac.kr

(®) This is an Open Access article distributed under the terms of the Creative Commons Attribution Non-Commercial License (http://creativecommons.org/ licenses/by-nc/3.0) which permits unrestricted non-commercial use, distribution, and reproduction in any medium, provided the original work is properly cited. survey report on reprocessing practices in Korea. The survey was administered to practitioners, including nurses and health technicians, involved in endoscope reprocessing at eight endoscopy units in academic or teaching hospitals. Sterilization may seriously damage flexible endoscopes; thus, high-level disinfection using liquid chemical disinfectants is accepted as the standard of care in reprocessing flexible endoscopes. Endoscope reprocessing, whether manual or automated, includes the following steps: precleaning, manual cleaning, disinfection, rinsing, drying, and storage. Park et al. ${ }^{6}$ found that most practitioners (98.9\%) complied with the established disinfection guidelines. Previous surveys on reprocessing practices conducted by the Disinfection Committee of the Korean Society of Gastrointestinal Endoscopy in 2002 and 2004 found that guideline compliance rates for reprocessing were $27 \%$ and $50 \%$, respectively. ${ }^{7}$ However, because the Park et al. ${ }^{6}$ survey participants were restricted to academic or teaching hospitals, the results cannot be directly compared with those of the previous surveys. Among the steps for endoscope reprocessing, transporting soiled endoscopes to reprocessing rooms in enclosed containers had the lowest compliance (56\%) in the present survey. The 2011 American Multisociety guidelines recommend that soiled endoscopes should be contained in a manner that prevents the exposure of staff, patients, or the environment to potentially infectious organisms during transport to the reprocessing area. ${ }^{4}$ Although open containers can be used to transport soiled endoscopes to immediately adjacent reprocessing areas, fully enclosed and labeled containers or bags should be used for transport to detached or distant reprocessing rooms. In the present survey, most practitioners (88\%) reported that their endoscopy units had separate, purpose-designed reprocessing rooms. Thus, it is important to separate contaminated and clean working areas to avoid recontamination of reprocessed endoscopes and accessories. Furthermore, the room should have proper ventilation or an 
exhaust system to minimize the risks associated with chemical vapors. ${ }^{3}$

In the present survey, orthophthaldehyde (OPA) was the most commonly used disinfectant $(44 \%)$, followed by peracetic acid (PAA, 35\%), glutaraldehyde (GA, 16\%), electrolyzed acid water (EAW, 4\%), and hydrogen peroxide (1\%). The aldehyde-based disinfectants (e.g., formaldehyde, GA, and OPA) are widely used and recommended by a number of guidelines. ${ }^{3,4}$ Although GA is the most commonly used disinfectant in several countries, the chemical's prominent vapor component is associated with ocular, nasal, and respiratory problems. ${ }^{8,9}$ OPA is an alternative to GA for high-level disinfection; however, as a potential skin and respiratory sensitizer, it may aggravate preexisting asthma, bronchitis, or dermatitis. ${ }^{9} \mathrm{~A}$ Portuguese national survey revealed that endoscopy units favored the use of PAA or EAW over aldehydes. ${ }^{10}$ The present survey showed an increase in the use of PAA compared with the surveys conducted in 2002 and 2004. Immersion of endoscopes in $2 \%$ GA for 20 minutes at $20^{\circ} \mathrm{C}$ is a widely accepted procedure for high-level disinfection. ${ }^{4}$ The immersion time in OPA is 5 minutes, which is significantly shorter than that for GA. Moreover, the time required for high-level disinfection in PAA is shorter than that required for GA (5 minutes for bacteria and 10 minutes for tubercle bacilli). ${ }^{11}$ Although immersion time according to disinfectant type was not assessed in the present survey, a considerable number of practitioners (63\%) reported adequate immersion time.

The use of disposable endoscopic accessories (e.g., disposable forceps, injection needles, and devices for polyp resection) is increasing in developed countries. Several endoscopy societies, including the European Society of Gastrointestinal Endoscopy and the Society of Gastroenterology Nurses and Associates, Inc., recommend the use of disposable injection needles. $^{3,12}$ Furthermore, injection needles are recommended for single use only. Reusable and disposable biopsy forceps are widely available for use in GI endoscopy units. Because reprocessing may damage or destroy the fragile devices, disposable forceps should be used only once. Although reusable biopsy forceps may be effectively reprocessed and sterilized, a clear tendency toward the use of disposable forceps has been observed. ${ }^{3}$ Recently, Lim et al. ${ }^{13}$ reported that disposable forceps performed better and cost less than reusable forceps. They found that the reprocessing of reusable forceps for one biopsy was calculated as 8,021 won. Thus, the use of disposable forceps for patients at high risk of infection is recommended. Park and colleagues ${ }^{6}$ found that one-third of respondents (37.4\%) reported that they reused disposable accessories. However, the methods for disinfection or sterilization of disposable accessories were not clearly indicated. Reuse of disposable accessories should be avoided to de- crease the risk of cross-infection in patients and staff. The reimbursement for the cost of endoscope reprocessing and disposable instruments is insufficient in Korea, suggesting the need for adequate compensation to avoid reuse.

Safety measures for endoscopists and their assistants have been established by the United States Occupational Safety and Health Administration, which requires employers to provide training and the necessary protective equipment and apparel, and the United States Centers for Disease Control and Prevention, which has developed guidelines for selection and use of personal protective equipment including gowns, gloves, eye protection/face shields, and masks. ${ }^{14}$ The present survey found that although most respondents reported having experienced occupational hazards, the majority (78\%) did not wear protective eyewear. The guidelines recommend that endoscopy unit staff should wear protective eyewear designed to provide adequate protection against risks such as a direct splash to the eye during endoscopic and reprocessing procedures and conjunctivitis and systemic infection, which can occur after touching the eyes with contaminated fingers or surgical implements. ${ }^{14,15}$ Because the individual agents for high-level disinfection are potentially toxic, precautions must be taken to avoid aerosolization of these agents during the early phases of endoscope reprocessing. Reprocessing staff should comply with the manufacturer's instructions to prevent occupational hazards.

Although the survey by Park et al. ${ }^{6}$ showed a good level of awareness of the importance of adequate endoscope reprocessing and good adherence to the current guidelines in Korea, it has some limitations. The survey included only participants from academic or teaching hospitals; thus, we cannot conclude that other endoscopy centers, including primary clinics, are in compliance with the endoscope reprocessing guidelines. Several guidelines underpin the importance of reprocessing quality assurance by recommending regular evaluation of reprocessing staff competence, regular microbiological inspection, and use of a reprocessing registry. ${ }^{3,4}$ Furthermore, endoscope reprocessing should be performed strictly according to the guidelines for patients with known infectious diseases. However, the present survey did not adequately evaluate these quality control issues. A future nationwide survey is necessary to evaluate compliance with national/international guidelines for quality assurance issues. Finally, reimbursement for adequate endoscope reprocessing or disposable instruments is essential, because inadequate reprocessing of endoscopes is high on the list of health technology hazards.

\section{Conflicts of Interest}

The author has no financial conflicts of interest. 


\section{REFERENCES}

1. Spach DH, Silverstein FE, Stamm WE. Transmission of infection by gastrointestinal endoscopy and bronchoscopy. Ann Intern Med 1993;118: 117-128.

2. Nelson DB. Infectious disease complications of GI endoscopy: part II, exogenous infections. Gastrointest Endosc 2003;57:695-711.

3. Beilenhoff U, Neumann CS, Rey JF, et al. ESGE-ESGENA Guideline: cleaning and disinfection in gastrointestinal endoscopy. Endoscopy 2008:40:939-957.

4. ASGE Quality Assurance In Endoscopy Committee, Petersen BT, Chennat J, et al. Multisociety guideline on reprocessing flexible gastrointestinal endoscopes: 2011. Gastrointest Endosc 2011;73:1075-1084.

5. Lee YK, Park JB. Steps of reprocessing and equipments. Clin Endosc 2013;46:274-279.

6. Park JB, Yang JN, Lim YJ, et al. Survey of endoscope reprocessing in Korea. Clin Endosc 2015;48:39-47.

7. Seol SY, Moon JS, Kae SH, et al. Result report of endoscope reprocessing survey: 2002 and 2004. Korean J Gastrointest Endosc 2005;30(Suppl 1):109S-118S.

8. Spinzi G, Fasoli R, Centenaro R, Minoli G; SIED Lombardia Working Group. Reprocessing in digestive endoscopy units in Lombardy: results of a regional survey. Dig Liver Dis 2008;40:890-896.

9. Zhang X, Kong J, Tang P, et al. Current status of cleaning and disinfection for gastrointestinal endoscopy in China: a survey of 122 endoscopy units. Dig Liver Dis 2011;43:305-308.

10. Soares JB, Gonçalves R, Banhudo A, Pedrosa J. Reprocessing practice in digestive endoscopy units of district hospitals: results of a Portuguese National Survey. Eur J Gastroenterol Hepatol 2011;23:1064-1068.

11. Park S, Jang JY, Koo JS, et al. A review of current disinfectants for gastrointestinal endoscopic reprocessing. Clin Endosc 2013;46:337-341.

12. Society of Gastroenterology Nurses and Associates, Inc. SGNA Standards: standards of infection control in reprocessing of flexible gastrointestinal endoscopes. Gastroenterol Nurs 2010;33:70-80.

13. Lim CH, Choi MG, Kim WC, et al. Performance and cost of disposable biopsy forceps in upper gastrointestinal endoscopy: comparison with reusable biopsy forceps. Clin Endosc 2012;45:62-66.

14. ASGE Technology Committee, Pedrosa MC, Farraye FA, et al. Minimizing occupational hazards in endoscopy: personal protective equipment, radiation safety, and ergonomics. Gastrointest Endosc 2010;72:227-235.

15. Benter T, Klühs L, Teichgräber UK, Riechert F, Ludwig WD, Dörken B. Need for safety goggles for endoscopy. Endoscopy 2003;35:803. 